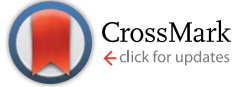

Cite this: RSC Adv., 2017, 7, 5701

Received 25th October 2016 Accepted 9th December 2016

DOI: $10.1039 / c 6 r a 25798 d$

www.rsc.org/advances

\section{Methane production enhancement from products of alkaline hydrogen peroxide pretreated sweet sorghum bagasse $\dagger$}

\begin{abstract}
Weixing Cao, Chen Sun, Xudong Li, ${ }^{*}$ Jiangping Qiu and Ronghou Liu
Alkaline hydrogen peroxide (AHP) pretreatment was applied to improve methane production from sweet sorghum bagasse under mesophilic conditions. After the pretreatment (solid-to-liquid ratio of $1: 10,2 \%$ $\mathrm{NaOH}$ at $121{ }^{\circ} \mathrm{C}$ for 60 min and then immersing with $5 \%(\mathrm{w} / \mathrm{v}) \mathrm{H}_{2} \mathrm{O}_{2}$ for $24 \mathrm{~h}$ at room temperature), pretreated bagasse, the pretreatment effluent and the pretreatment mixture, together with the untreated bagasse, were used as substrates for methane production under the same volatile solid (VS) loading and digestion conditions. The AHP pretreatment resulted in lignin removal and different degrees of methane production. The methane production of bagasse was improved from $262.1 \pm 7.3 \mathrm{~mL} \mathrm{CH}_{4}$ per g VS to $330.4 \pm 1.3 \mathrm{~mL} \mathrm{CH}_{4}$ per $\mathrm{g}$ VS. The pretreatment mixture and pretreatment effluent could be successfully digested and both of the methane productions were higher than the untreated bagasse, although there were degrees of inhibition. In view of the bagasse recovery during the pretreatment, total methane production from separate digestion of pretreated bagasse and pretreatment effluent was $18.6 \%$ more than untreated bagasse based on the same mass of dry sweet sorghum bagasse. The kinetic analysis implied that the Cone model showed a better fit to the experimental data of untreated bagasse, pretreated bagasse and pretreatment effluent, and the Fitzhugh model was better to predict the methane production of the pretreatment mixture. AHP pretreatment could increase the methane production rate of sweet sorghum bagasse. These results will provide a reference to the methane production from AHP pretreated sweet sorghum bagasse in industry.
\end{abstract}

\section{Introduction}

Sweet sorghum is a type of non-grain perennial plant and is considered to be an excellent raw material for ethanol production via fermentation due to the abundant fermentable carbohydrates (glucose, fructose, and sucrose) in the juice of the stem. ${ }^{1}$ The sweet sorghum bagasse inevitably contains considerable soluble sugar, which can be directly converted to renewable energy after being squeezed. In addition to the fermentable carbohydrates, there is plentiful cellulose and hemicellulose in the bagasse, which are usually used to produce ethanol or methane after pretreatment and enzymatic hydrolysis. There is approximately $20 \%$ lignin in the bagasse, which will hinder the accessibility of the enzyme to cellulose and hemicellulose.$^{2-4}$ Consequently, pretreatment before hydrolysis is needed to make the carbohydrate susceptible towards enzymatic or bacterial attacks.

Department of Resources and Environment, School of Agriculture and Biology, Shanghai Jiao Tong University, 800 Dongchuan Road, Minhang District, Shanghai, China 200240. E-mail: lixudong@sjtu.edu.cn; Fax: +86-21-34205765; Tel: +86-2134205765

$\dagger$ Electronic supplementary information (ESI) available. See DOI: $10.1039 / \mathrm{c} 6 \mathrm{ra} 25798 \mathrm{~d}$
Many researchers have summarized the lignocellulose pretreatment methods including physical, chemical and biological pretreatment or combination of these methods. ${ }^{5-9}$ Alkaline peroxide hydrogen (AHP) pretreatment was considered to be one of the most efficient methods for removing the majority of lignin while retaining most of the cellulose and hemicellulose. ${ }^{2,10}$ AHP pretreatment has potential advantages relating to process simplicity, feedstock handling, capital costs, and compatibility with enzymatic hydrolysis as compared to other pretreatment methods for lignocellulose biomass. ${ }^{11}$ After pretreatment, sugar recovery and the ethanol yield or methane production of the sweet sorghum bagasse were significantly improved., ${ }^{2,10,12}$ In addition, the hydrolysate from AHPpretreated bagasse and by-products from ethanol production could be used to produce biogas via anaerobic digestion. ${ }^{13,14}$ However, alkaline pretreatment also have certain drawbacks, such as low recovery rate of biomass and high concentration of salt retention. ${ }^{10}$

The pretreated bagasse slurry will divide into two fractions after AHP pretreatment. The solid fraction can easily be converted to biofuels through hydrolysis and fermentation. The liquid fraction contain salt and soluble organic matter, which may be result of inhibition on digestion because of the high osmotic pressure. ${ }^{10}$ It will be toxic for the biogas production if 
the $\mathrm{Na}^{+}$concentration is as high as $10-11 \mathrm{~g} \mathrm{Na} \mathrm{L}{ }^{-1} \cdot{ }^{15}$ Furthermore, the phenols and carboxylic acids generated from the delignification will also inhibit the biogas production. ${ }^{16}$ Posttreatment of the pretreated bagasse through washing will cause soluble sugar losses and cost increase. ${ }^{17}$

There have been numerous studies examining the methane production improvement from AHP pretreated bagasse, but biogas production from pretreatment effluent has not been reported as far as we know. The pretreatment effluent is a type of alkaline waste solution that contains an alkali metal ion and phenolic compounds. In fact, there are considerable fermentable substances in the effluent, such as free soluble sugars and organic matters from degradation of cellulose and hemicellulose during pretreatment, which should be utilized. It is meaningful to study the methane production of AHP pretreatment effluent for both environmental and energy related concerns.

The aims of this paper were to (1) evaluate the feasibility of biogas production from sweet sorghum bagasse and the pretreatment effluent, (2) investigate the enhancement effect of AHP pretreatment on biogas production from sweet sorghum bagasse, and (3) compare the kinetic parameters of biogas production using existing models.

\section{Materials and methods}

\subsection{Raw materials and reagents}

Sweet sorghum stalks were obtained from Shunan village, Chongming district, Shanghai. The juice and bagasse were separated by squeezing with a laboratory-scale squeezer. The bagasses without washing were dried to constant weight at $45{ }^{\circ} \mathrm{C}$ before milled and sieved to pass through a 40-mesh sieve (particles smaller than $0.420 \mathrm{~mm}$ ), sealed in plastic bag, and subsequently stored at $4{ }^{\circ} \mathrm{C}$.

\subsection{AHP pretreatment process}

Sweet sorghum bagasse was first soaked in $2 \%(\mathrm{w} / \mathrm{w}) \mathrm{NaOH}$ solution for $5 \mathrm{~min}$ with the solid-to-liquid ratio of $1: 10$, and then was autoclaved at $121{ }^{\circ} \mathrm{C}$ for $60 \mathrm{~min}$. After the autoclaved slurry was cooled down to room temperature, $30 \% \mathrm{H}_{2} \mathrm{O}_{2}(\mathrm{w} / \mathrm{w})$ was added to maintain the $\mathrm{H}_{2} \mathrm{O}_{2}$ concentration in solution up to $5 \%(\mathrm{w} / \mathrm{w})$. The slurry was kept darkness for $24 \mathrm{~h}$ at room temperature and pressure. The detailed pretreatment process was described in our previous research. ${ }^{2,12}$ Two sets sweet sorghum bagasse samples were pretreated by AHP. One of which was separated by vacuum filtration with a glass microfibre filter $(4.5-9 \mu \mathrm{m})$. The solid fraction and liquid fraction are named pretreated bagasse and pretreatment effluent. The other set was named pretreatment mixture. The effluent and pretreatment mixture were adjusted with approximately $10 \mathrm{~mol}$ $\mathrm{L}^{-1} \mathrm{HCl}$ solution until reaching a $\mathrm{pH}$ of $8.0 \pm 0.2$ before using. Untreated bagasse acted as the control. Each assay was duplicated and the results were averaged.

\subsection{Methane production assays}

Batch methane production tests were carried out in duplicate using $500 \mathrm{~mL}$ conical flasks with an effective volume of $400 \mathrm{~mL}$ at $37 \pm 0.5{ }^{\circ} \mathrm{C}$. The co-digested cow and chicken manure in our lab-reactors was used as inoculum. The $\mathrm{pH}$, total solids (TS) and volatile solids (VS) of the inoculum were $8.16,3.92 \mathrm{~g} \mathrm{~kg}^{-1}$ and $2.28 \mathrm{~g} \mathrm{~kg}^{-1}$ fresh weight. The ratio of inoculum to substrate was 1.5 : 1 (based on VS). The methane production assays with cellulose under the same conditions were set as the positive blanks to evaluate the reliability of the apparatus. The inoculums and substrates were added to conical flasks before the headspaces of the bottles were flushed with pure $\mathrm{N}_{2}$ for $1 \mathrm{~min}$ to maintain anaerobic conditions. The prepared bottles were sealed with rubber stoppers immediately. All digesters were manually shaken for about 10 seconds every day. The daily biogas production was determined by displacement of water. The accumulative biogas production was calculated by subtracting the control. The methane production was recalculated into standard volume at standard temperature and pressure $(273.15 \mathrm{~K}, 101.325 \mathrm{kPa})$ after methane content determination. ${ }^{\mathbf{1 8}}$ All the analytical tests were duplicated and the results were averaged.

\subsection{Analytical methods}

TS and VS of the bagasse were determined according to the APHA methods. ${ }^{19}$ The total phenolic content was determined by the Folin-Ciocalteu reagent method. Gallic acid was used as the standard..$^{20}$ The neutral detergent fiber (NDF), acid detergent fiber (ADF) and acid detergent lignin (ADL) were measured by Van Soest's method, and cellulose and hemicellulose were calculated. ${ }^{21}$ The lignin content including acid soluble lignin (ASL) and acid insoluble lignin (AIL) were determined by standard methods (NREL/TP-510-42617 and NREL/TP-510-42618). The methane content in the biogas was tested by gas chromatography (GC, Agilent 7890A). ${ }^{22}$

\subsection{Calculations}

Recovery rate $\left(R_{\mathrm{r}}\right)$ of bagasse was expressed by eqn (1),

$$
R_{\mathrm{r}}=W_{1} / W_{2} \times 100
$$

where $R_{\mathrm{r}}$ is the recovery rate expressed as a percentage, $W_{1}$ and $W_{2}$ are the dry sample masses after and before AHP pretreatment, respectively.

Theoretical methane production of sweet sorghum bagasse was calculated according to elemental analysis results and Buswell's equation mentioned in many literatures. ${ }^{23,24}$

The biodegradability was of sweet sorghum bagasse was calculated according to eqn (2). ${ }^{25}$

$$
B_{\mathrm{d}}(\%)=P_{1} / P_{2} \times 100 \%
$$

where $B_{\mathrm{d}}$ is the biodegradability expressed as a percentage, $P_{1}$ and $P_{2}$ are the experimental and theoretical methane production, respectively.

\subsection{Kinetic models}

In this study, Fitzhugh, ${ }^{26}$ Cone, ${ }^{26}$ Monomolecular ${ }^{27}$ and Gompertz $^{\mathbf{2 8}}$ models were selected to fit the experiment data. The 
Table 1 The selected models for describing methane production ${ }^{a}$

\begin{tabular}{ll}
\hline Model & Expression \\
\hline Monomolecular & $Y=P\left(1-\mathrm{e}^{-k(t-L)}\right)$ \\
Fitzhugh & $Y=P\left(1-\mathrm{e}^{-k t}\right)^{n}$ \\
Cone & $Y=\frac{P}{1+(k t)^{-n}}$ \\
Gompertz & $\left.Y=P \mathrm{e}^{\left(-\frac{2.7182 R_{\mathrm{m}}(L-t)}{P}+1\right.}\right)$
\end{tabular}

${ }^{a} Y$ is methane production ( $\mathrm{mL} \mathrm{CH}_{4}$ per $\mathrm{g}$ VS), $P$ is methane production potential $\left(\mathrm{mL} \mathrm{CH}_{4}\right.$ per $\left.\mathrm{g} \mathrm{VS}\right), k$ is rate constant $\left(\mathrm{d}^{-1}\right), t$ is digestion time (d), $R_{\mathrm{m}}$ is the maximum methane production rate $\left(\mathrm{mL} \mathrm{CH}_{4}\right.$ per $\mathrm{g}$ VS per d), $L$ is length of the lag phase (d), and $n$ is shape factor, dimensionless.

domain for all selected models was $t \geq 0$. Model equations are shown in Table 1.

Model parameters were estimated using the nonlinear least squares fitting tool in OriginPro. ${ }^{29}$ The models evaluation was based on root mean square prediction error (RMSPE) and Akaike's information criterion (AIC). ${ }^{\mathbf{1 8 , 3 0}}$

\section{Results and discussion}

\subsection{Effect of AHP pretreatment on the main composition of bagasse}

The main composition of AHP pretreated bagasse and untreated bagasses were analyzed and the results were shown in Table 2.

According to Table 2, the cellulose content was notably increased, while the VS content decreased less than $0.1 \%$. The cellulose content of pretreated bagasse is as high as $72 \%$, which is about 2.4 times more than the control. The hemicellulose was also decreased slightly. The recovery rate in this paper was only $42.77 \%$, which was much less than Cao's research, ${ }^{12}$ this could be explained by not washing with sweet sorghum bagasse and pretreatment method. The acid soluble lignin (ASL) decreased approximately $22 \%$ and the acid insoluble lignin (AIL) content of bagasse decreased as much as $66 \%$. This finding implies the main effect for lignin removal of AHP to bagasse is AIL removal.

Table 2 The main composition of bagasse before/after pretreatment

\begin{tabular}{|c|c|c|}
\hline Items & Untreated bagasse & Pretreated bagasse \\
\hline TS (\%) & $90.81 \pm 0.07$ & $95.09 \pm 0.04$ \\
\hline VS (\%, TS basis) & $97.44 \pm 0.02$ & $97.35 \pm 0.25$ \\
\hline NDF (\%) & $56.01 \pm 0.32$ & $93.41 \pm 0.29$ \\
\hline Cellulose (\%) & $30.58 \pm 0.62$ & $72.03 \pm 1.13$ \\
\hline Hemicellulose (\%) & $19.82 \pm 0.41$ & $18.29 \pm 0.52$ \\
\hline $\operatorname{ASL}^{a}(\%)$ & $6.71 \pm 0.01$ & $5.25 \pm 0.09$ \\
\hline $\mathrm{AIL}^{b}(\%)$ & $16.18 \pm 0.98$ & $5.57 \pm 0.71$ \\
\hline C (\%, TS basis) & $45.02 \pm 0.19$ & $43.38 \pm 0.04$ \\
\hline $\mathrm{H}(\%, \mathrm{TS}$ basis $)$ & $6.72 \pm 0.28$ & $6.91 \pm 0.13$ \\
\hline $\mathrm{N}$ (\%, TS basis) & $0.72 \pm 0.01$ & $0.22 \pm 0.05$ \\
\hline O (\%, TS basis) & $44.99 \pm 0.46$ & $46.85 \pm 0.04$ \\
\hline Recovery rate (\%) & Null & $42.77 \pm 1.47$ \\
\hline
\end{tabular}

The removal of AIL was beneficial to the enzymatic hydrolysis. According to Cao's research, after being extracted by a squeezer, the bagasse was washed by boiling water three times to remove the free sugar remains in the bagasse to avoid the interference to the latter enzymatic hydrolysis. In this paper, the sugar and other soluble materials was retained in the pretreatment effluent and might result in the relatively low recovery rate. These soluble materials remained in the effluent should be recycled to reduce the pretreatment cost.

The neutral detergent fibre (NDF) content of pretreated bagasse was $93.41 \%$, which was almost 2 times more than the control, which illustrated that the major soluble materials, such as sugar, protein and fat were transferred into the effluent because of the pretreatment. This significant amount of soluble material should be recycled. The results of elemental analysis in Table 2 showed that the AHP pretreatment lead to carbon and nitrogen contents reduction, as well as the increase of hydrogen and oxygen content. As the lignin mainly consisted of benzene rings, carbon was carried away in the form of phenolic compounds during delignification..$^{22,31}$

\subsection{Methane production assays}

The daily methane production and cumulative methane production of untreated bagasse, pretreated mixture, pretreated bagasse and pretreatment effluent are shown in Fig. 1.

According to Fig. 1, the maximum daily methane production was found in the fifth day. The maximum daily methane production of untreated bagasse, pretreated mixture, pretreated bagasse and pretreatment effluent were $37.0 \mathrm{~mL} \mathrm{~g}^{-1} \mathrm{VS}, 35.3 \mathrm{~mL}$ $\mathrm{g}^{-1} \mathrm{VS}, 66.8 \mathrm{~mL} \mathrm{~g}^{-1} \mathrm{VS}$ and $30.9 \mathrm{~mL} \mathrm{~g}^{-1} \mathrm{VS}$, respectively. It was obviously that the AHP pretreatment was beneficial to increase the maximum methane production. After 30 days, the cumulative methane production of untreated bagasse, pretreated mixture, pretreated bagasses and pretreatment effluent were $262.1 \mathrm{~mL} \mathrm{CH}_{4}$ per $\mathrm{g}$ VS, $269.9 \mathrm{~mL} \mathrm{CH}_{4}$ per $\mathrm{g} \mathrm{VS}, 330.4 \mathrm{~mL} \mathrm{CH}_{4}$ per $\mathrm{g}$ VS and $296.4 \mathrm{~mL} \mathrm{CH}_{4}$ per $\mathrm{g}$ VS, respectively. The final methane production of pretreated bagasse was $26 \%$ and $12.8 \%$ more than untreated bagasse and the effluent, respectively. It was obvious that the methane production of the sweet sorghum bagasse was improved after AHP pretreatment based on the same mass of vS loading. Sambusiti et al. ${ }^{32}$ also proved that pretreatment with a $\mathrm{NaOH}$ solution at $10 \mathrm{~g} \mathrm{NaOH}$ per $100 \mathrm{~g}$ TS dosage, maintained at $55{ }^{\circ} \mathrm{C}$ for $12 \mathrm{~h}$, can increase methane yield of ensiled sorghum forage up to $324.5 \pm 0.7 \mathrm{~mL} \mathrm{CH}_{4}$ per $\mathrm{g}$ VS. Antonopoulou ${ }^{33}$ reported that thermal treatment could improve the methane yield only from 253 to $288 \mathrm{~L} \mathrm{CH}_{4}$ per $\mathrm{kg}$ sorghum. Many studies have demonstrated AHP pretreatment could increase ethanol or methane yield of the bagasse, however, the digestion of pretreatment effluent was rarely studied. In this paper, the methane production of the effluent was higher than untreated bagasse under current conditions. This finding implied the digestion of effluent could not be neglected because considerable clean energy could be obtained from the effluent.

As seen in Fig. 1, the cumulative methane production curves of the four substrates are sigmoid. The cumulative methane 


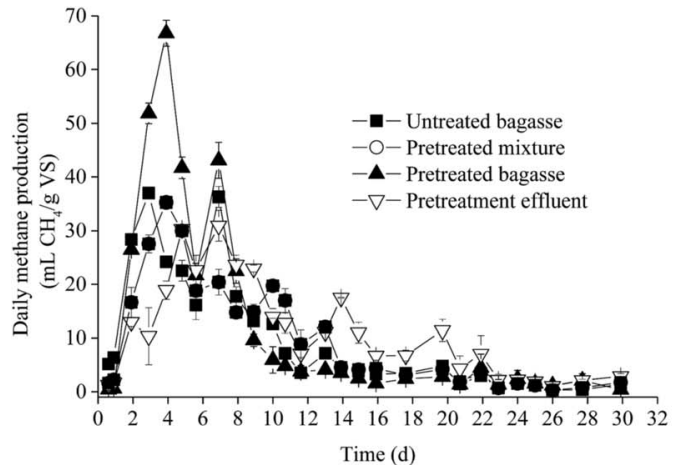

(a) Daily methane production

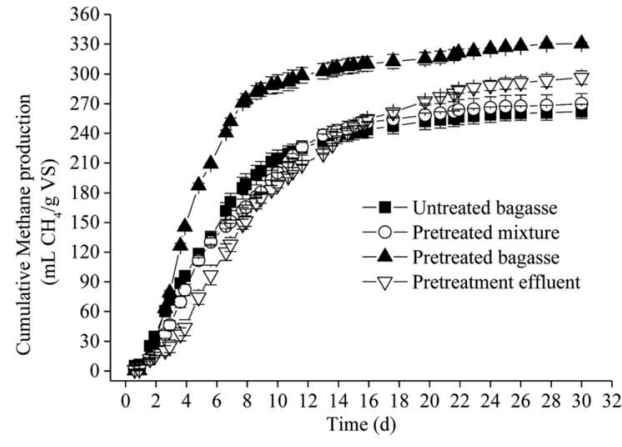

(b) Cumulative methane production

Fig. 1 Daily and cumulative methane production of untreated bagasse, pretreated mixture, pretreated bagasse and pretreatment effluent.

productions of all substrates were first increased slowly and later accelerated until $20 \mathrm{~d}$ and then were close to the final methane production except for pretreatment effluent. As we know, lignin is the key inhibition factor in lignocellulose degradation. Delignification will be beneficial to the cellulose and hemicellulose enzymatic hydrolysis and methanogenesis. In our previous research, ${ }^{2,12}$ the scanning electron microscope, nuclear magnetic resonance and Fourier transform infrared spectrum analysis of pretreatment bagasse supported that AHP pretreatment was effective for enzymatic hydrolysis enhancement.

The accumulative methane production tendency of pretreatment effluent was similar to the pretreated/untreated bagasses. The accumulative methane production of pretreatment effluent before $16 \mathrm{~d}$ was lower than pretreated/untreated bagasse. After $16 \mathrm{~d}$, the pretreatment effluent's methane production was higher than that of untreated bagasse but slightly lower than that of pretreated bagasse. Due to the AHP pretreatment, the soluble sugars remain on the bagasse after extraction, and the carbohydrates generated because of the lignocellulose degradation were transferred to the pretreatment effluent. These carbohydrates could be converted to methane by methanogens under suitable condition. In fact, as seen from Fig. 1, the accumulative methane production from pretreated mixture was close to the untreated bagasse under the same conditions. However, the effluent took longer time than the mixture to reach the maximum methane production. This finding implies a negative effect of the pretreatment on methane production. Because $2 \% \mathrm{NaOH}$ was used to pretreat the bagasse, $\mathrm{Na}^{+}$concentration in the effluent was approximately $10.6 \mathrm{~g} \mathrm{~L} \mathrm{~L}^{-1}$ after being neutralized with $\mathrm{HCl}$ solution. Even considering the dilution of inoculum, the initial $\mathrm{Na}^{+}$ concentration in effluent could up to approximately $2.63 \mathrm{~g} \mathrm{~L}^{-1}$. High concentrations of salts will decrease cell activity and result in dehydration of bacterial cells due to increase in osmotic pressure, which inhibits the anaerobic digestion process. ${ }^{33,34}$ According to Feijoo's research ${ }^{35}$ if $\mathrm{Na}^{+}$concentrations ranged from 3 to $16 \mathrm{~g} \mathrm{~L}^{-1}$, it would result in $50 \%$ inhibition of methanogenic activity. This finding may explain the low methane production of pretreatment effluent before $16 \mathrm{~d}$. Not only would the saline ions inhibit the digestion, but the phenolic compounds generated from chemical pretreatment will also be toxic for microorganisms. ${ }^{5,33}$ Cao reported the total phenolic compounds (TPCs) after AHP pretreatment in effluent was approximately $1.85 \mathrm{~g} \mathrm{~L}^{-1}$, and speculated on potential inhibition effect. In this paper, the TPCs of effluent were $1.47 \mathrm{~g} \mathrm{~L}^{-1}$ $(7.8 \mathrm{mM})$. With consideration to the dilution effect of inoculum, the initial concentration of the digestion was approximately $0.36 \mathrm{~g} \mathrm{~L}^{-1}(1.91 \mathrm{mM})$. Olguin-Lora et al. reported alkyl phenols (phenol, $o-, m-, p$-cresol, 3,4-dimethylphenol and 2-ethylphenol) would result in $50 \%$ inhibition of specific methanogenic activity at concentrations ranging from 1.6 to $5.0 \mathrm{mM}$ for unadapted granular sludge. ${ }^{36}$ It was not difficult to understand the high TPCs was one of the inhibition factors for methane production.

\subsection{Theoretical methane production and the biodegradability evaluation}

Table 3 shows theoretical methane production and biodegradability from four substrates. The theoretical methane production of bagasse was evaluated based on elemental analysis shown in Table 3 according to the Buswell equation.

As seen from Table 3, after anaerobic digestion for $30 \mathrm{~d}$, the biodegradability of pretreated bagasse is approximate $30 \%$

Table 3 The theoretical methane production and biodegradation rate of four substrates

\begin{tabular}{|c|c|c|c|c|}
\hline Items & $\mathrm{BMP}_{\mathrm{T}}{ }^{a}$ & $\mathrm{BMP}_{\mathrm{O}}$ & Biodegradability (\%) & $\mathrm{BMP}_{\mathrm{O}}$ \\
\hline $\begin{array}{l}\text { Untreated } \\
\text { bagasse }\end{array}$ & $456.2 \pm 11.5$ & $262.1 \pm 7.3$ & 57.5 & 25.5 \\
\hline $\begin{array}{l}\text { Pretreated } \\
\text { mixture }\end{array}$ & $456.2 \pm 11.5$ & $269.9 \pm 10.2$ & 59.2 & 26.3 \\
\hline $\begin{array}{l}\text { Pretreated } \\
\text { bagasse }\end{array}$ & $442.9 \pm 3.8$ & $330.4 \pm 1.3$ & 74.6 & 13.8 \\
\hline $\begin{array}{l}\text { Pretreatment } \\
\text { effluent }\end{array}$ & 395.7 & $296.4 \pm 6.8$ & 74.9 & 16.5 \\
\hline
\end{tabular}

${ }^{a} \mathrm{BMP}_{\mathrm{T}}$ : theoretical biochemical methane potential, $\mathrm{mL} \mathrm{CH}_{4}$ per $\mathrm{g}$ VS. $\mathrm{BMP}_{\mathrm{O}}$ : experimental biochemical methane potential, $\mathrm{mL} \mathrm{CH}_{4}$ per $\mathrm{g}$ VS. $\mathrm{BMP}_{\mathrm{O}^{\prime}}$ : methane production, $\mathrm{L} \mathrm{CH}_{4}$ per $100 \mathrm{~g}$ TS. 
higher than untreated bagasse. This finding implies that AHP pretreatment makes sweet sorghum bagasse become more degradable, which is correspond to Sun's research. ${ }^{22}$ For pretreatment effluent, the biodegradability was as high as $74.9 \%$, which was considerably higher than the others. The reason may be attributed to the fermentable carbohydrates in effluent. According to Fig. 1, although the time to maximum cumulative methane production of pretreatment effluent was longer than the others, the final experimental methane production from pretreatment effluent was close to the theoretical methane production. Although the biodegradability of pretreated mixture was slightly higher than untreated bagasse, there was no significant difference between untreated bagasse and pretreated mixture in aspects of methane production according to a one way analysis of variance $(p=0.4728>0.05)$.

As we know, although most of the researches reported the enhancement on methane production via AHP pretreatment, there were more or less dry materials losses during the pretreatment. For some sacchariferous lignocellulose such as sugarcane and sweet sorghum bagasse, the soluble carbohydrates originated from the bagasse or generated during the pretreatment were digestible. It is necessary to evaluate the effect of AHP pretreatment on methane production of sweet sorghum bagasse based on the same mass of dry materials when considering the economy evaluation on AHP pretreatment. In this study, the dry materials recovery rate was only 42.77\%. According to Table 3, 25.5 L and 26.3 L methane could be produced based on $100 \mathrm{~g}$ untreated dry sweet sorghum bagasse and pretreated mixture, respectively, while $13.8 \mathrm{~L}$ and 16.5 L methane could be produced from the pretreated bagasse and pretreatment effluent, respectively. In this case, $18.6 \%$ more methane than the control could be produced by AHP pretreatment and digested separately base on the same mass of dry bagasse loading. Consequently, although there are no difference on methane production between untreated bagasse and pretreated mixture, the methane production will be increased when the solid and liquid fraction of pretreatment mixture was digested separately. Anyway, the AHP pretreatment could enhance methane production under the current conditions.

\subsection{Kinetic models of biogas production}

The methane production curves of untreated bagasse, pretreated mixture, pretreated bagasse and pretreatment effluent in this paper resemble sigmoid curve. Methane productions for all variables were fitted based on Fitzhugh, Cone, Monomolecular and Gompertz models. The RMSPE values stand for the deviation between predicted and experimental values. AIC was employed based on information technology to compare goodness-of-fit of models. The adaptive model will be selected with the minimum RMSPE and AIC value. ${ }^{37}$ According to the results of model tests (data not shown), the Cone mode was selected to fit the experimental methane production of untreated bagasse, pretreated bagasse and pretreatment effluent, and the Fitzhugh model was suitable for fitting the data of pretreated mixture. The parameters estimation of best model is shown in Table 4.

As shown in Table 4, the $R^{2}$ of these fittings exceed 0.997, which demonstrates good fitness between experimental and predicted values. The pretreated bagasse manifested both the highest maximum methane production rate and the highest methane production under the same VS loading, while pretreatment effluent had the lowest methane production rate. This finding also illustrated that AHP pretreatment accelerated the methane production rate. Besides, inhibition effect was shown by the methane production performance from the effluent or the mixture. In this paper, the concentration of sodion is as high as $11.5 \mathrm{~g} \mathrm{Na}^{+} \mathrm{L}^{-1}$, corresponding to $\mathrm{NaOH}(2 \%$ $\mathrm{w} / \mathrm{v})$. It is well known that sodium cation at above $8 \mathrm{~g} \mathrm{~L}^{-1}(1.5 \%$ $\mathrm{w} / \mathrm{v}$ ) was inhibitory to anaerobic digestion process. $^{38-40}$ In addition, the sugars degradation and lignin disruption during AHP pretreatment may generate soluble phenolic compounds with inhibitory effect on methanogenic microorganisms. ${ }^{33}$ In this respect, the decrease in methane yields in this paper could be attributed to a partial inhibition or toxicity of methanogens by high sodium ion and TPCs concentrations. To overcome a possible inhibition, the use of another alkali (such as

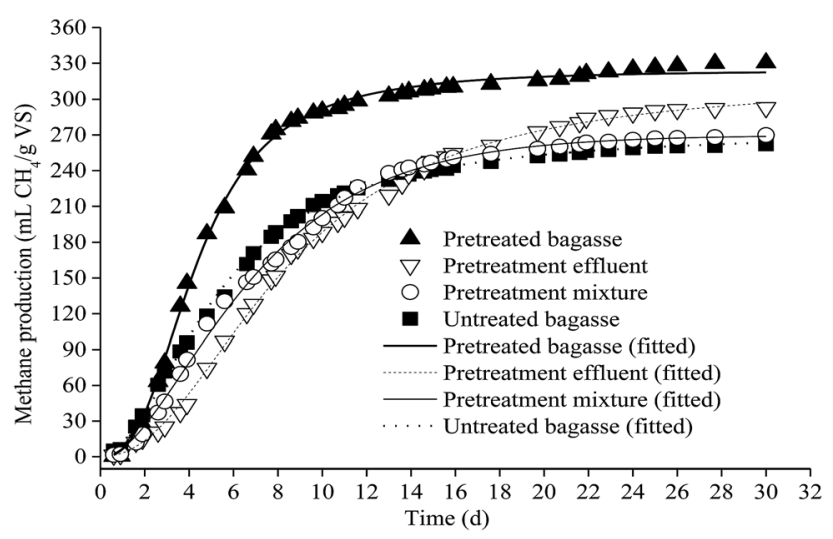

Fig. 2 The experimental and predicted methane production from untreated bagasse and the mixture of pretreated bagasse and the effluent.

Table 4 Estimated parameters of the selected model

\begin{tabular}{|c|c|c|c|c|}
\hline Parameters & Untreated bagasse & Pretreated mixture & Pretreated bagasse & Pretreatment effluent \\
\hline$P\left(\mathrm{~mL} \mathrm{CH}_{4}\right.$ per $\left.\mathrm{g} \mathrm{VS}\right)$ & $272.75 \pm 1.45$ & $269.82 \pm 1.55$ & $324.24 \pm 1.39$ & $315.41 \pm 2.62$ \\
\hline$k$ & $0.19 \pm 0.00$ & $0.21 \pm 0.01$ & $0.23 \pm 0.00$ & $0.12 \pm 0.00$ \\
\hline$n$ & $1.93 \pm 0.03$ & $2.18 \pm 0.09$ & $2.65 \pm 0.06$ & $2.17 \pm 0.04$ \\
\hline$R^{2}$ & 0.9989 & 0.9978 & 0.9982 & 0.9988 \\
\hline
\end{tabular}




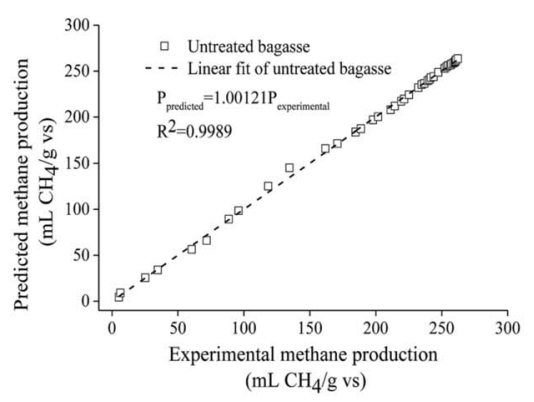

(a)

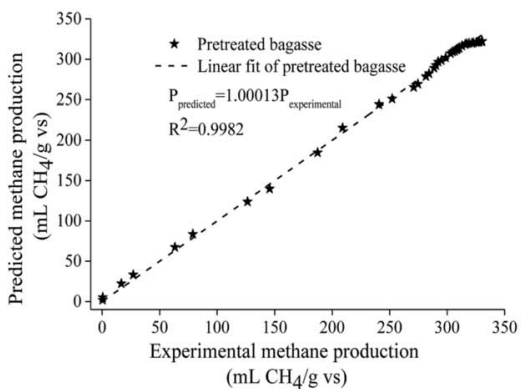

(c)

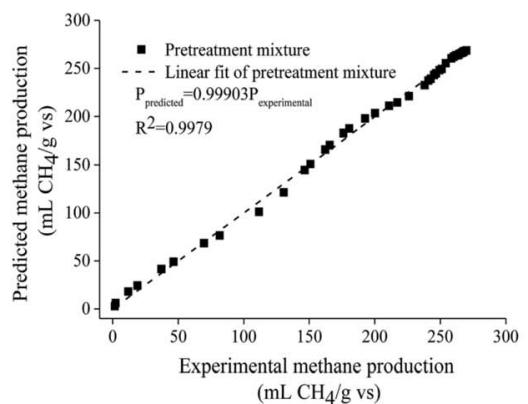

(b)

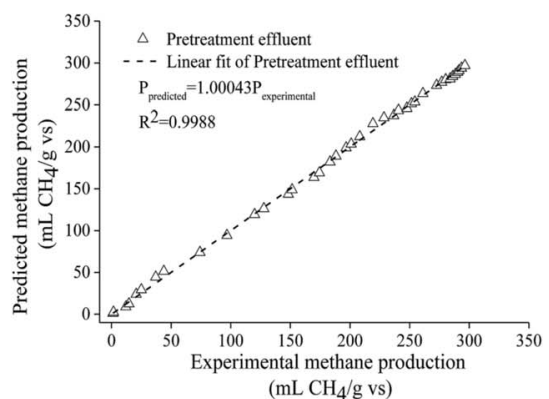

(d)

Fig. 3 Predicted methane production of different substrate against experimental data.

potassium or calcium) or could be a solution. Because the inhibitory effect of potassium to methanogens was relatively weak and the digestate could be used as fertilizer. The calcium could be removed through sedimentation by bubbled into $\mathrm{CO}_{2}$ after pretreatment. The other solution for weakening the inhibition effect from high sodium ion and TPCs concentrations were to reduce the concentration of $\mathrm{NaOH}$ solution during pretreatment or increasing the I/S ratio during the digestion. ${ }^{41}$

The equations for predicting methane productions from different substrates were shown as follows.

$$
\text { Untreated bagasse : } Y=\frac{272.75}{1+(0.19 t)^{-1.93}}
$$

Pretreatment mixture: $Y=269.82\left(1-\mathrm{e}^{-0.21 t}\right)^{2.18}$

$$
\begin{gathered}
\text { Pretreated bagasse }: Y=\frac{324.24}{1+(0.23 t)^{-2.65}} \\
\text { Pretreatment effluent : } Y=\frac{315.41}{1+(0.12 t)^{-2.17}}
\end{gathered}
$$

Fig. 2 shows experimental and predicted methane production as a function of digestion time. Fig. 3 shows predicted methane production of different substrate against experimental data. The results showed a very good fit between predicted methane production and experimental values $\left(R^{2}>0.99\right)$. The selected models are suitable for describing the methane production from mentioned four substrates.

\section{Conclusions}

AHP could improve methane production for sweet sorghum bagasse according to the methane production process and kinetic analysis. Methane production from pretreated bagasse was as high as $330.4 \pm 1.3 \mathrm{~mL} \mathrm{CH}_{4}$ per $\mathrm{g}$ VS, which was $26 \%$ higher than the untreated bagasse. The digestion process of pretreatment effluent indicated there was an inhibition effect during methane production, and the biodegradation rate could reach approximately $74.9 \%$. Sweet sorghum bagasse pretreated by AHP could produce $18.6 \%$ more methane than could the untreated bagasse, when the solid and the liquid fractions of pretreatment mixture were digested separately to achieve the holistic utilization.

\section{Acknowledgements}

This work was supported by the financial support from "Special Fund for Agro-scientific Research in the Public Interest of China (201303089)" and "China Postdoctoral Science Foundation funded project (2015M571568)".

\section{References}

1 N. B. Appiah-Nkansah, K. Zhang, W. Rooney and D. Wang, Ind. Crops Prod., 2016, 83, 654-662. 
2 W. Cao, C. Sun, J. Qiu, X. Li, R. Liu and L. Zhang, Korean J. Chem. Eng., 2016, 33, 873-879.

3 S. M. Kim, B. S. Dien and V. Singh, Biotechnol. Biofuels, 2016, 9, 1-15.

4 F. Shen, J. N. Saddler, R. Liu, L. Lin, S. Deng, Y. Zhang, G. Yang, H. Xiao and Y. Li, Carbohydr. Polym., 2011, 86, 1542-1548.

5 Y. Zheng, J. Zhao, F. Xu and Y. Li, Prog. Energy Combust. Sci., 2014, 42, 35-53.

6 S. Behera, R. Arora, N. Nandhagopal and S. Kumar, Renewable Sustainable Energy Rev., 2014, 36, 91-106.

7 C. Zhong, C. Wang, F. Wang, H. Jia, P. Wei and Y. Zhao, RSC $A d v .$, 2016, 6, 60187-60195.

8 R. Singh, A. Shukla, S. Tiwari and M. Srivastava, Renewable Sustainable Energy Rev., 2014, 32, 713-728.

9 S. Fu, X. Shi, F. Wang, X. Yuan and R. Guo, RSC Adv., 2015, 5, 63903-63908.

10 G. Banerjee, S. Car, J. S. Scott-Craig, D. B. Hodge and J. D. Walton, Biotechnol. Biofuels, 2011, 4, 1-15.

11 G. Banerjee, S. Car, T. Liu, D. L. Williams, S. L. Meza, J. D. Walton and D. B. Hodge, Biotechnol. Bioeng., 2012, 109, 922-931.

12 W. Cao, C. Sun, R. Liu, R. Yin and X. Wu, Bioresour. Technol., 2012, 111, 215-221.

13 P. Kaparaju, M. Serrano and I. Angelidaki, Bioresour. Technol., 2009, 100, 6317-6323.

14 F. De Paoli, A. Bauer, C. Leonhartsberger, B. Amon and T. Amon, Bioresour. Technol., 2011, 102, 6621-6624.

15 M. H. Gerardi, The Microbiology of Anaerobic Digesters (Wastewater Microbiology Series), Wiley-Interscience, A John Wiley \& Sons, 2003.

16 H. B. Klinke, A. B. Thomsen and B. K. Ahring, Appl. Microbiol. Biotechnol., 2004, 66, 10-26.

17 Y. S. Cheng, Y. Zheng, C. W. Yu, T. M. Dooley, B. M. Jenkins and J. S. VanderGheynst, Appl. Biochem. Biotechnol., 2010, 162, 1768-1784.

18 C. Sun, W. Cao and R. Liu, Appl. Biochem. Biotechnol., 2015, 177, 985-995.

19 APHA, Standard Methods for the Examination of Water and waste water, American Public Health Association, Washington, DC, USA, 2005.

20 V. L. Singleton, R. Orthofer and R. M. Lamuela-Raventós, Methods Enzymol., 1999, 299, 152-178.
21 P. J. Van Soest, J.-Assoc. Off. Anal. Chem., 1963, 46, 829-835. 22 C. Sun, R. Liu, W. Cao, R. Yin, Y. Mei and L. Zhang, Energy Fuels, 2015, 29, 4966-4975.

23 Y. Li, R. Zhang, C. Chen, G. Liu, Y. He and X. Liu, Bioresour. Technol., 2013, 149, 406-412.

24 A. M. Buswell and H. F. Mueller, Ind. Eng. Chem., 1952, 44, 550-552.

25 E. Elbeshbishy, G. Nakhla and H. Hafez, Bioresour. Technol., 2012, 110, 18-25.

26 R. E. Pitt, T. L. Cross, A. N. Pell, P. Schofield and P. H. Doane, Math. Biosci., 1999, 159, 145-163.

27 M. Schulin-Zeuthen, E. Kebreab, W. J. Gerrits, S. Lopez, M. Z. Fan, R. S. Dias and J. France, J. Anim. Sci., 2007, 85, 1953-1961.

28 M. H. Zwietering, I. Jongenburger, F. M. Rombouts and K. van't Riet, Appl. Environ. Microbiol., 1990, 56, 1875-1881. 29 M. L. Johnson, Methods Cell Biol., 2008, 84, 781-805.

30 H. M. El-Mashad, Bioresour. Technol., 2013, 132, 305-312.

31 M. Li, C. Foster, S. Kelkar, Y. Pu, D. Holmes, A. Ragauskas, C. M. Saffron and D. B. Hodge, Biotechnol. Biofuels, 2012, 5, 1-15.

32 C. Sambusiti, E. Ficara, F. Malpei, J. P. Steyer and H. Carrère, Waste Biomass Valorization, 2013, 4, 549-556.

33 G. Antonopoulou and G. Lyberatos, Waste Biomass Valorization, 2013, 4, 583-591.

34 Y. Chen, J. J. Cheng and K. S. Creamer, Bioresour. Technol., 2008, 99, 4044-4064.

35 G. Feijoo, M. Soto, R. Méndez and J. M. Lema, Enzyme Microb. Technol., 1995, 17, 180-188.

36 P. Olguin-Lora, L. Puig-Grajales and E. Razo-Flores, Environ. Technol., 2003, 24, 999-1006.

37 H. Motulsky and A. Christopoulos, Fitting models to biological data using linear and nonlinear regression: a practical guide to curve fitting, Graph Pad Software Inc, San Diego, CA, USA, 2003.

38 R. Gebauer, Bioresour. Technol., 2004, 93, 155-167.

39 D. Georgacakis and D. Sievers, Trans. ASABE, 1979, 22, 01620168.

40 P. L. McCarty, Public Works, 1964, 95, 91-94.

41 I. Angelidaki, M. Alves, D. Bolzonella, L. Borzacconi, J. L. Campos, A. J. Guwy, S. Kalyuzhnyi, P. Jenicek and J. B. van Lier, Water Sci. Technol., 2009, 59, 927-934. 